\title{
Clustering Algorithm Based on Density of Data
}

\author{
Yong $\mathrm{Ma}^{1, *}$ \\ ${ }^{1}$ Science College of Liaoning Technical University Fuxin, Liaoning, 123000, China
}

\begin{abstract}
The k_means clustering algorithm has very extensive application. The paper gives out_in clustering algorithm based on density. The algorithm combines distance with data density to adapt to data distribution. It can effectively solve the clustering of data. Out_in clustering based on density reduce distorition by move out and move in. Simulation results show that out in clustering algorithm is more effective than the k_means clustering algorithm.
\end{abstract}

\section{Introduction}

Clustering algorithm have very extensive application in pattern recognition. There are several ways to achieve clustering, such as Gas Ref[1-4], Clustering Algorithm based on Sofm Ref[5-8]. Ref[9] gives a clustering algorithm based on density. DBSCAN clustering algorithm is also density-based, and it is typical based on different data densities, it is an effective method to solve the clustering problem of different data distributions. The paper gives Out_in clustering algorithm based on density. The algorithm can effectively solve clustering problem of different data distributions, the local density of data is taken as the probability of data element in this paper. The advantage of mean clustering algorithm is that the mean is the optimal clustering center based on Euclidean metric. Average is widely used Ref[10-11]. Howerer, Euclidean distance alone is not enough. Based on probability of data and probability of clusters, the paper proposes a distortion function. And the distortion function is minimized by local strategy. Out_in clustering algorithm based on density uses local density as probability of data element and uses density of clusters as probability of clusters. According to the statistical characteristics of data, the probability distribution between clusters should be different. In out_in clustering algorithm based on density, Euclidean distance combined with probability distributions, at the same time, mean is still the clustering center, thus adapting to different data distributions. The simulation results show that Out_in clustering algorithm based on density converges quickly. Clustering algorithm is widely used in vector quantization image compression[12-16], Out_in clustering algorithm based on density is same.

\section{Text}

Theorem 1: Given data distribution: $\mathrm{p}\left\{\mathrm{X}=\mathrm{x}_{\mathrm{k}}\right\}=\mathrm{p}_{\mathrm{k}} \mathrm{k}=1$,
$2 \ldots$ n. $p_{\mathrm{k}}$ is probability of $\mathrm{x}_{\mathrm{k}} \cdot \mathrm{p}_{1}+\mathrm{p}_{2}+\ldots+\mathrm{p}_{\mathrm{n}}=1$. Mathematical expectation $E=p_{1} x_{1}+p_{2} x_{2}+\ldots+p_{n} x_{n}$. Base on the Euclidean metric, the optimal cluster center of the given data distribution is $E=p_{1} x_{1}+p_{2} x_{2}+\ldots+p_{n}$ $\mathrm{x}_{\mathrm{n}}$.

Proof: Let $\mathrm{C}$ is the clustering center of the given data distribution, the distortion $\mathrm{S}=\mathrm{p}_{1} \quad\left(\mathrm{x}_{1}-\mathrm{C}\right)^{2+} \mathrm{p}_{2} \quad\left(\mathrm{x}_{2}-\mathrm{C}\right)$ ${ }^{2}+\ldots+p_{n}\left(x_{n}-C\right)^{2}$.

According to the extreme value theorem, $\mathrm{d} \mathrm{S} / \mathrm{d} \mathrm{C}=0$,

$-2 \mathrm{p}_{1}\left(\mathrm{x}_{1}-\mathrm{C}\right)-2 \mathrm{p}_{2}\left(\mathrm{x}_{2}-\mathrm{C}\right)-\ldots-2 \mathrm{p}_{\mathrm{n}}\left(\mathrm{x}_{\mathrm{n}}-\mathrm{C}\right)=0$ $\left.\mathrm{p}_{\mathrm{n}}\right)$

So, $C=\left(p_{1} x_{1}+p_{2} x_{2}+\ldots+p_{n} x_{n}\right) /\left(p_{1}+p_{2}+\ldots+\right.$

$\mathrm{p}_{1}+\mathrm{p}_{2}+\ldots+\mathrm{p}_{\mathrm{n}}=1$

$\mathrm{C}=\mathrm{p}_{1} \mathrm{x}_{1}+\mathrm{p}_{2} \mathrm{x}_{2}+\ldots+\mathrm{p}_{\mathrm{n}} \mathrm{x}_{\mathrm{n}}$

So, the optimal clustering center of the given data distribution is $E=p_{1} x_{1}+p_{2} x_{2}+\ldots+p_{n} x_{n}$.

Q. E. D.

Theorem 1 gives a meaningful result about mathematical expectation. For multidimensional data, Theorem 1 is the same holds true. Proof is needed to use partial derivative. For the equal probability data distribution, the optimal clustering center of given data distribution is $\mathrm{E}=\left(\mathrm{x}_{1}+\mathrm{x}_{2}+\ldots+\mathrm{x}_{\mathrm{n}}\right) / \mathrm{n}$, it is average value. For multidimensional data, the optimal clustering center of given data distribution is average vector. Of course, need to assume that components of vector are independent.

Theorem 2: If $(\Omega, \psi, \mathrm{P})$ is probability $\operatorname{space}(\Omega$ is sample space, $\psi$ is event domain, $\mathrm{P}($.$) is the probability$ defined in $(\Omega, \psi)), \quad \mathrm{B}_{1}, \quad \mathrm{~B}_{2}, \ldots, \mathrm{B}_{\mathrm{n}}$ is pairwise incompatible positive probability events, $\mathrm{B}_{\mathrm{i}} \mathrm{B}_{\mathrm{j}}=\Phi, \mathrm{i}, \mathrm{j}=1$, $2, \ldots, n ; P\left(B_{k}\right)>0, k=1,2, \ldots, n$; $A$ is sbubset of $B=\cup B_{k}$, then

$$
\text { Proof: } \quad \begin{aligned}
& \because A \text { is sbubset of } B=\cup B_{k} \\
& \therefore A=A B=A\left(\cup B_{k}\right)=A B_{1} \cup A B_{2} \cup \ldots A B_{n} \\
& \because B_{i} B_{j}=\Phi, i, j=1,2, \ldots, n \\
& \therefore\left(A B_{i}\right)\left(A B_{j}\right)=\Phi, i, j=1,2, \ldots, n
\end{aligned}
$$

*e-mail: mayongly@163.com 


$$
\begin{gathered}
\because \mathrm{P}\left(\mathrm{B}_{\mathrm{k}}\right)>0, \mathrm{k}=1,2, \ldots, \mathrm{n} \\
\therefore \mathrm{P}(\mathrm{A})=\mathrm{P}\left(\mathrm{AB}_{1}\right)+\mathrm{P}\left(\mathrm{AB}_{2}\right)+\ldots+\mathrm{P}\left(\mathrm{AB}_{\mathrm{n}}\right) \\
=\mathrm{P}\left(\mathrm{A} \mid \mathrm{B}_{1}\right) \mathrm{P}\left(\mathrm{B}_{1}\right)+\mathrm{P}\left(\mathrm{A} \mid \mathrm{B}_{2}\right) \mathrm{P}\left(\mathrm{B}_{2}\right)+\ldots+\mathrm{P}\left(\mathrm{A} \mid \mathrm{B}_{\mathrm{n}}\right) \\
=\sum \mathrm{P}\left(\mathrm{A} \mid \mathrm{B}_{\mathrm{k}}\right) \mathrm{P}\left(\mathrm{B}_{\mathrm{k}}\right)
\end{gathered}
$$

Q. E. D.

Theorem 2 show that total probability theorem in Ref[17-18] is inference of Theorem 2.

The clustering problem: The given data distribution: $\mathrm{p}\left\{\mathrm{X}=\mathrm{x}_{\mathrm{k}}\right\}=\mathrm{p}_{\mathrm{k}} \mathrm{k}=1,2 \ldots \mathrm{n} . \mathrm{p}_{\mathrm{k}}$ is the probability of $\mathrm{x}_{\mathrm{k}}, \mathrm{p}_{1}+$ $\mathrm{p}_{2}+\ldots+\mathrm{p}_{\mathrm{n}}=1$. Divide $\mathrm{x}_{1}, \mathrm{x}_{2} \ldots \mathrm{x}_{\mathrm{n}}$ into $\mathrm{m}$ clusters.

The general situation is discussed below. The optimal solution of the problem is almost impossible to calculate. The strategy of finding the local optimal solution is adopted. Although k-means algorithm adopts local strategy, the actual effect is very good. Out_in clustering algorithm based on density also uses a local strategy to find the optimal solution from the current clustering result. Of course, in most case the local optimal solution is found. A distortion function is given below, according to the Theorem 2. Here, adopt euclidean metric. The distortion function is related to distance and probability distribution, therefore clustering is not limited to spherical clusters. The process can be understood as such a random event: (1)In $\mathrm{x}_{1}, \mathrm{x}_{2}, \ldots, \mathrm{x}_{\mathrm{n}}$, select an element $x_{k}$. (2)Put $x_{k}$ to a cluster. (1) and (2) are independent. According to Theorem 2 ,

$\mathrm{J}=\Sigma \mathrm{q}_{\mathrm{k}} \Sigma \mathrm{p}_{\mathrm{t}} \Sigma\left(\mathrm{x}_{\mathrm{tj}}-\mathrm{c}_{\mathrm{kj}}\right)^{2} \mathrm{x}_{\mathrm{t}}, \mathrm{c}_{\mathrm{kj}}$ is the jth component of $\mathrm{x}_{\mathrm{t}}, \mathrm{c}_{\mathrm{k}}$

Adopts local strategy,

$$
\text { Min } \mathrm{J}=\Sigma \mathrm{q}_{\mathrm{k}} \Sigma \mathrm{p}_{\mathrm{t}} \Sigma\left(\mathrm{x}_{\mathrm{tj}}-\mathrm{c}_{\mathrm{kj}}\right)^{2}
$$

Probability of cluster $k$ is $Q_{k}, q_{k}=Q_{k} / n u m$, num is number of elements in cluster $\mathrm{k}, \mathrm{c}_{\mathrm{k}}$ is the clustering center of cluster $k, x_{t}$ is in cluster $k$, Probability of $x_{t}$ is $p_{t}$. Out_in clustering algorithm based on density uses local density as probability of data. In out in clustering algorithm based on density, for any data element, move out first from the cluster; then to select the cluster with the least distortion, move in data element to the cluster. In order to simplify the calculation, do the following appropriate derivation, suiutable for fast iteration:

If $x_{t}$ selects cluster $k$, to move in. Be divided into two conditions: (1) $\mathrm{x}_{\mathrm{t}}$ is not in cluster $\mathrm{k},(2) \mathrm{x}_{\mathrm{t}}$ is in cluster $\mathrm{k}$.

(1) Let $\mathrm{s}_{\mathrm{k}}=\mathrm{p}_{1} \sum\left(\mathrm{x}_{1 \mathrm{j}}-\mathrm{c}_{\mathrm{kj}}\right)^{2}+\ldots+\mathrm{p}_{\mathrm{h}} \sum\left(\mathrm{x}_{\mathrm{hj}}-\mathrm{c}_{\mathrm{kj}}\right)^{2}$, distortion function $J=\Sigma q_{k} S_{k}$. In the above model, based on the local strategy, for cluster $\mathrm{k}$, assume that components of vector are independent, at the same time, assume that clusters are independent. The optimal clustering center is $c_{k}=\left(p_{1}\right.$ $\left.\mathrm{x}_{1}+\ldots+\mathrm{p}_{\mathrm{h}} \mathrm{x}_{\mathrm{h}}\right) /\left(\mathrm{p}_{1}+\ldots+\mathrm{p}_{\mathrm{h}}\right)$, similarly to the proof of Theorem 1. If $x_{t}$ selects cluster $k$, then new clustering center of cluster $k$ is $C_{k}=\left(p_{1} x_{1}+\ldots+p_{h} x_{h}+p_{t} x_{t}\right) /\left(p_{1}\right.$ $\left.+\ldots+p_{h}+p_{t}\right), p_{t}$ is probability of $x_{t}, q_{k}$ is the probability of cluster $\mathrm{k}$.

$$
\begin{aligned}
& \text { Let } \mathrm{S}_{\mathrm{k}}=\mathrm{p}_{1} \sum\left(\mathrm{x}_{\mathrm{lj}}-\mathrm{C}_{\mathrm{kj}}\right)^{2}+\ldots+\mathrm{p}_{\mathrm{h}} \sum\left(\mathrm{x}_{\mathrm{hj}}-\mathrm{C}_{\mathrm{kj}}\right)^{2}+\mathrm{p}_{\mathrm{t}} \sum\left(\mathrm{x}_{\mathrm{tj}}\right. \\
& \left.-\mathrm{C}_{\mathrm{kj}}\right)^{2} \\
& \mathrm{~S}_{\mathrm{k}}-\mathrm{S}_{\mathrm{k}}=\mathrm{p}_{1} \sum\left(\mathrm{x}_{1 \mathrm{j}}-\mathrm{C}_{\mathrm{kj}}\right)^{2}+\ldots+\mathrm{p}_{\mathrm{h}} \sum\left(\mathrm{x}_{\mathrm{hj}}-\mathrm{C}_{\mathrm{kj}}\right)^{2}+\mathrm{p}_{\mathrm{t}} \sum\left(\mathrm{x}_{\mathrm{tj}}\right. \\
& \left.-\mathrm{C}_{\mathrm{kj}}\right)^{2}-\Sigma \mathrm{p}_{\mathrm{i}} \sum\left(\mathrm{x}_{\mathrm{ij}}-\mathrm{c}_{\mathrm{kj}}\right)^{2}
\end{aligned}
$$

$$
\begin{aligned}
& \because\left(\mathrm{p}_{1} \mathrm{x}_{1}+\ldots+\mathrm{p}_{\mathrm{h}} \mathrm{x}_{\mathrm{h}}\right)=\left(\mathrm{p}_{1}+\ldots+\mathrm{p}_{\mathrm{h}}\right) \mathrm{c}_{\mathrm{k}} \\
& \therefore=\left(\mathrm{p}_{1}+\ldots+\mathrm{p}_{\mathrm{h}}\right) \sum\left(\mathrm{c}_{\mathrm{kj}}-\mathrm{C}_{\mathrm{kj}}\right)^{2}+\mathrm{p}_{\mathrm{t}} \sum\left(\mathrm{x}_{\mathrm{tj}}-\mathrm{C}_{\mathrm{kj}}\right)^{2} \\
& =\left(\mathrm{p}_{1}+\ldots+\mathrm{p}_{\mathrm{h}}\right) \mathrm{p}_{\mathrm{t}}{ }^{2} /\left(\mathrm{p}_{1}+\ldots+\mathrm{p}_{\mathrm{h}}+\mathrm{p}_{\mathrm{t}}\right)^{2} \sum\left(\mathrm{x}_{\mathrm{tj}}-\mathrm{c}_{\mathrm{kj}}\right)^{2+} \\
& \mathrm{p}_{\mathrm{t}} \sum\left(\mathrm{x}_{\mathrm{tj}} \mathrm{C}_{\mathrm{kj}}\right)^{2} \\
& =\mathrm{p}_{\mathrm{t}}^{2}\left(\mathrm{p}_{1}+\ldots+\mathrm{p}_{\mathrm{h}}\right) /\left(\mathrm{p}_{1}+\ldots+\mathrm{p}_{\mathrm{h}}+\mathrm{p}_{\mathrm{t}}\right)^{2} \sum\left(\mathrm{x}_{\mathrm{tj}}-\mathrm{c}_{\mathrm{kj}}\right)^{2}+\mathrm{p}_{\mathrm{t}}\left(\mathrm{p}_{1}\right. \\
& \left.+\ldots+p_{h}\right)^{2} /\left(p_{1}+\ldots+p_{h}+p_{t}\right)^{2} \sum\left(x_{\mathrm{tj}}-c_{k j}\right)^{2} \\
& =\mathrm{p}_{\mathrm{t}}\left(\mathrm{p}_{1}+\ldots+\mathrm{p}_{\mathrm{h}}\right) /\left(\mathrm{p}_{1}+\ldots+\mathrm{p}_{\mathrm{h}}+\mathrm{p}_{\mathrm{t}}\right) \sum\left(\mathrm{x}_{\mathrm{tj}}-\mathrm{c}_{\mathrm{kj}}\right)^{2} \\
& \mathrm{~S}_{\mathrm{k}}=\mathrm{s}_{\mathrm{k}}+\mathrm{p}_{\mathrm{t}}\left(\mathrm{p}_{1}+\ldots+\mathrm{p}_{\mathrm{h}}\right) /\left(\mathrm{p}_{1}+\ldots+\mathrm{p}_{\mathrm{h}}+\mathrm{p}_{\mathrm{t}}\right) \sum\left(\mathrm{x}_{\mathrm{i} j}-\mathrm{c}_{\mathrm{k} j}\right)^{2}
\end{aligned}
$$

Let $\mathrm{Q}_{\mathrm{k}}=\mathrm{p}_{1}+\ldots+\mathrm{p}_{\mathrm{h}}$ is probability of cluster $\mathrm{k}, \mathrm{q}_{\mathrm{k}}=$ $\mathrm{Q}_{\mathrm{k}} / \mathrm{h}$, then the increase distortion of the cluster $\mathrm{k}$ is:

$$
I J_{k}=\left(\left(Q_{k}+p_{t}\right) /(h+1)\right) S_{k}-\left(Q_{k} / h\right) S_{k}
$$

(2) If $\mathrm{x}_{\mathrm{t}}$ is in cluster $\mathrm{k}$, similarly,

$$
\begin{aligned}
& \text { Let } \mathrm{s}_{\mathrm{k}}=\mathrm{p}_{1} \sum\left(\mathrm{x}_{\mathrm{lj}}-\mathrm{c}_{\mathrm{kj}}\right)^{2}+\ldots+\mathrm{p}_{\mathrm{h}} \sum\left(\mathrm{x}_{\mathrm{hj}}-\mathrm{c}_{\mathrm{kj}}\right)^{2}+\mathrm{p}_{\mathrm{t}} \sum\left(\mathrm{x}_{\mathrm{tj}}-\mathrm{c}_{\mathrm{kj}}\right)^{2} \text {, } \\
& c_{k}=\left(p_{1} x_{1}+\ldots+p_{h} x_{h}+p_{t} x_{t}\right) /\left(p_{1}+\ldots+p_{h}+p_{t}\right) \\
& \mathrm{C}_{\mathrm{k}}=\left(\mathrm{p}_{1} \mathrm{x}_{1}+\ldots+\mathrm{p}_{\mathrm{h}} \mathrm{x}_{\mathrm{h}}\right) /\left(\mathrm{p}_{1}+\ldots+\mathrm{p}_{\mathrm{h}}\right) \\
& \mathrm{S}_{\mathrm{k}}=\mathrm{p}_{1} \sum\left(\mathrm{x}_{\mathrm{lj}}-\mathrm{C}_{\mathrm{kj}}\right)^{2}+\ldots+\mathrm{p}_{\mathrm{h}} \sum\left(\mathrm{x}_{\mathrm{hj}}-\mathrm{C}_{\mathrm{kj}}\right)^{2} \\
& \mathrm{~s}_{\mathrm{k}}-\mathrm{S}_{\mathrm{k}}=\mathrm{p}_{1} \sum\left(\mathrm{x}_{\mathrm{lj}}-\mathrm{c}_{\mathrm{kj}}\right)^{2}+\ldots+\mathrm{p}_{\mathrm{h}} \sum\left(\mathrm{x}_{\mathrm{hj}}-\mathrm{c}_{\mathrm{kj}}\right)^{2}+\mathrm{p}_{\mathrm{t}} \sum\left(\mathrm{x}_{\mathrm{jt}}-\mathrm{c}_{\mathrm{kj}}\right)^{2}- \\
& \mathrm{p}_{1} \sum\left(\mathrm{x}_{1 \mathrm{j}}-\mathrm{C}_{\mathrm{kj}}\right)-\ldots-\mathrm{p}_{\mathrm{h}} \sum\left(\mathrm{x}_{\mathrm{hj}}-\mathrm{C}_{\mathrm{kj}}\right)^{2} \\
& =\left(\mathrm{p}_{1}+\ldots+\mathrm{p}_{\mathrm{h}}\right) \sum\left(\mathrm{c}_{\mathrm{kj}}-\mathrm{C}_{\mathrm{kj}}\right)^{2}+\mathrm{p}_{\mathrm{t}} \sum\left(\mathrm{x}_{\mathrm{tj}}-\mathrm{c}_{\mathrm{kj}}\right)^{2} \\
& =\mathrm{p}_{\mathrm{t}}^{2}\left(\mathrm{p}_{1}+\ldots+\mathrm{p}_{\mathrm{h}}\right) /\left(\mathrm{p}_{1}+\ldots+\mathrm{p}_{\mathrm{h}}+\right. \\
& \left.\mathrm{p}_{\mathrm{t}}\right)^{2} \sum\left(\mathrm{x}_{\mathrm{tj}}-\mathrm{C}_{\mathrm{kj}}\right)^{2}+\mathrm{p}_{\mathrm{t}} \sum\left(\mathrm{x}_{\mathrm{tj}}-\mathrm{c}_{\mathrm{kj}}\right)^{2} \\
& \left.=\left(\mathrm{p}_{\mathrm{t}}^{2} /\left(\mathrm{p}_{1}+\ldots+\mathrm{p}_{\mathrm{h}}\right)\right) \sum\left(\mathrm{x}_{\mathrm{tj}}-\mathrm{c}_{\mathrm{kj}}\right)^{2}\right)+\mathrm{p}_{\mathrm{t}} \sum\left(\mathrm{x}_{\mathrm{tj}}-\mathrm{c}_{\mathrm{kj}}\right)^{2} \\
& =\mathrm{p}_{\mathrm{t}}\left(\mathrm{p}_{1}+\ldots+\mathrm{p}_{\mathrm{h}}+\mathrm{p}_{\mathrm{t}}\right) /\left(\mathrm{p}_{1}+\ldots+\mathrm{p}_{\mathrm{h}}\right) \sum\left(\mathrm{x}_{\mathrm{tj}}-\mathrm{c}_{\mathrm{kj}}\right)^{2} \\
& \mathrm{~S}_{\mathrm{k}}=\mathrm{s}_{\mathrm{k}}-\mathrm{p}_{\mathrm{t}}\left(\mathrm{p}_{1}+\ldots+\mathrm{p}_{\mathrm{h}}+\mathrm{p}_{\mathrm{t}}\right) /\left(\mathrm{p}_{1}+\ldots+\mathrm{p}_{\mathrm{h}}\right) \sum\left(\mathrm{x}_{\mathrm{t} j}-\mathrm{c}_{\mathrm{kj}}\right)^{2}(4)
\end{aligned}
$$

Let probability of cluster $k$ is $\mathrm{Q}_{\mathrm{k}}=\mathrm{p}_{1}+\ldots+\mathrm{p}_{\mathrm{h}}+\mathrm{p}_{\mathrm{t}}$, $\mathrm{q}_{\mathrm{k}}=\mathrm{Q}_{\mathrm{k}} /(\mathrm{h}+1)$, then the increase distortion of the cluster $\mathrm{k}$ is:

$$
\text { I J } J_{k}=\left(Q_{k} /(h+1)\right) S_{k}-\left(\left(Q_{k}-p_{t}\right) / h\right) S_{k}
$$

Out_in clustering algorithm based on density uses local density as probability of data. This can be achieved by grid division. The data space is divided into grids. Count the number of data elements in the grid, the density of each grid unit is determined. uses the density of each grid unit as the probability of the grid. The size of grid affects the probability distribution of data. Therefore, the appropriate grid edge length should be selected to reflect the probability distribution of data. In Out_in clustering algorithm based on density, the order in which grid elements select clusters has an impact on the clustering results. So, the operation is performed in the order from small probability grid element to large probability grid element. In this way, give small probability grid elements a chance to cluster. Here, a grid element used as data in clustering algorithm. Specifically, the grid is replaced by the average value of data elements in the grid. Uses the probability of grids in the cluster as the probability of the cluster. 
Algorithm 1 (Out_in clustering algorithm based on density):

1 To select randomly $\mathrm{m}$ unrepeated data from $\mathrm{x}_{1}$, $\mathrm{x}_{2} \ldots \mathrm{x}_{\mathrm{n}}$, to become the initial clustering centers: $\mathrm{c}_{1}$, $\mathrm{c}_{2} \ldots \mathrm{c}_{\mathrm{m}}$.

2 The remaining data elements select the cluster according to formula (3), to move in.

Any one $\mathrm{x}_{\mathrm{t}}, \mathrm{I} \mathrm{J}_{\mathrm{o}}=\min \left\{\mathrm{I} \mathrm{k}_{\mathrm{k}}\right\}, \mathrm{k}=1,2 \ldots \mathrm{m}$. Cluster $\mathrm{o}$ is selected.

3 Any one $x_{t}, t=1,2, \ldots n$; To move out first.

Then to move in,

If $\mathrm{x}_{\mathrm{t}}$ is in cluster $\mathrm{k}$

Compute $\mathrm{I} \mathrm{J}_{\mathrm{k}}$ according to formula (5)

Else

Compute I $\mathrm{J}_{\mathrm{k}}$ according to formula (3)

End if

$I J_{o}=\min \left\{\mathrm{IJ}_{\mathrm{k}}\right\}, \mathrm{k}=1,2 \ldots \mathrm{m}$. cluster o is selected.

Compute cluster parameters: total probability, number of elements in the cluster, mean value.

4 If the convergence condition is not satisfied GoTo 3

Else

End if End

Theorem 3: Algorithm 1 converges to extreme point.

Proof: In each iteration of the Algorithm 1. The distortion $\mathrm{J}$ is monotonically decreasing.

The distortion $\mathbf{J}$ is monotonically decreasing and is bounded,

So Algorithm 1 converges.

Let the currently clustering centers is the optimal clustering centers,

The distortion $\mathrm{J}$ is monotonically decreasing, according to Algorithm 1.

Algorithm 1 converges to the optimal clustering centers,

So, Algorithm1 converges to extreme point.

Q.E.D.

\section{Simulation}

The software of the simulation is MATLAB 2012a. Vector quantization of image.is applied to simulations. The simulation original image is LENNA $(256 * 256)$, and Algorithm 1 is compared with k-means algorithm. The standard uses mean square error (MSE), the edge length of grid is 8 . The number of clusters is 256 . Because the initial clustering center has random factors, the simulation was done 5 times. The simulation results are given in table 1. Algorithm 1 converges quickly. The result of simulation explains that Algorithm 1 is more effective compared with the k-means algorithm. Simulation results show that Out in clustering algorithm based on density is more effective than the k-means clustering algorithm for clustering problem, average performance improve $165.3 \%$, as shown in TABLE 1. At the same time, simulation results show that the distortion function is effective.
TABLE 1: MSE of reconstructed image

\begin{tabular}{|l|l|l|l|}
\hline Number of times & 1 & 2 & 3 \\
\hline Algorithm 1 & 38.40 & 38.26 & 37.46 \\
\hline K-means & 45.28 & 45.24 & 44.74 \\
\hline Number of times & 4 & 5 & average \\
\hline Algorithm 1 & 36.81 & 37.55 & 37.70 \\
\hline K-means & 45.36 & 45.21 & 45.17 \\
\hline
\end{tabular}

\section{Conclusion}

Simulation results show that Out_in clustering algorithm based on density can process cludtering problem. Out_in clustering algorithm based on density adapt to different data distribution, while retaining the characteristics of kmeans clustering algorithm. The clustering method base on kmeans algorithm is spherical clustering method, which can only solve the convex clustering problem. In Out_in clustering algorithm based on density, probalility distribution is introduced, so Out_in clustering algorithm based on densit can also solve the non_convex clustering problem. At the same time, due to the introduction of probability distribution in Out in clustering algorithm based on densit, result of clustering is different to the convex clustering problem. This paper deals with the clustering problem by mathematical statistics method, and obtains a meaningful conclusion. In out_in clustering algorithm based on density, Euclidean distance combined with probability distributions, can deal with both convex and non convex data clustering problems. Analysis on clustering of non convex data will be given in the following paper.

\section{References}

1. Wu Yue-xian, A Genetic Algorithms Based Clustering Method and Its Application, Computer Simulation, 2007(11).

2. Wang Jiayao, A Genetic K-means Algorithm for Spatial Clustering, Computer Engineering, 2006(2)

3. Yong Ma, Optimization design of under mine wireless sensor network based on genetic quantum algorithm. 2009 Chinese Control and Decision Conference, CCDC 2009. IEEE Computer Society. (CA). EI Accession. Article number:5194818. http://www.engineeringvillage.com/controllere/servl et/Controller?EIS

4. Yong Ma, Optimization design of under coal mine wireless body sensor network based on genetic algorithm. Proceedings-Intermational Conference on Networks Security,Wireless Communications and Trusted Computing, NSWCTC2009. (CA).EI Accession. Article number: 4908481. http://www.engineeringvillage.com/controllere/servl et/Controller?EIS

5. Ni Bu-xi, Clustering analysis based on SOFM network, Computer Engineering and Design, 2006(3)..

6. Ma Yong, Improved Embedded Zerotree Wavelet 
Coding Based on The Vector Quantization, Computer Systems Applications, 2012(1), 160-163.

7. Yong Ma, Combined Kohonen Neural Netwoks and Multiresolution Approach Method for Fractal Image Compression. Proceedings of the International Conference on Sensing, Computing and Automation. Copyright $@ 2006$ Watam Press, 2356-2360.

8. Ma Yong, Method of high-speed fractal image compression proceeding and its VLSI implementation. journal of tanjin ploytechnic university, 2006(4),54-56

9. Alex Rodriguez Alessandro Laio, Clustering by fast search and find of density peaks[j], Sc[ience, 2014, 344(6191):1492-1496.

10. Y. Ma, Reesearch on error limited histogram. Computer Engineering and Application, 2000(2): 63-64.

11. Y. Ma, More Reesearch on error limited histogram. Computer Engineering and Application, 2000(3): 80-81.

12. M. E. Blain and T. R. Fischer, "A comparison of Vector Quantization Techniques in Transform and Subband Coding of Imagery, "Signal Precessing: Image Communication, 3 (1): 91-105, 1991

13. Dasarathy, Belur V. (ed) (1995) Image Data Compression: Block Truncation coding (BTC) Techniques, Los Alamitos, CA, IEEE Computer Society Press.

14. Dewitte, J. And J. Ronson (1983) “Original Block Coding Scheme for Low Bit Rate Image Transmission," in Signal Processing II: Theories and Application-Proceeding of EUSIPCO 83, H. W. Schussler, ed. , Amsterlam, Zelsevier Science Publishers B. V. (NorthHolland), pp. 143-146.

15. Ronson, J. And J. Dewitte (1992) “ Adaptive Block Trunction Coding Scherme Using an Edge Following Algorithm, "Proceedings of the IEEE Internationa Conference on Acoustics, Speech, and Signal Processing, Piscataway, NJ, IEEE Press, PP. $1235-1238$

16. Lee T, Peterson AM. Adaptive Vector Quan tization Using a Self-Development Neural Netwo rk. IEEE J. Select Areas in Commum, 1990, 8(8): 1458-1471.

17. SiJian Yan and XiuFang Liu, Probability and Mathematical Statistics, 1990(4), ISBN 7-04-002836 $-0 / 0.895$

18. LeiFu Gao, Wei Li, SuYing Shi, XiaoHua Peng; Newly Edited Probability and Mathematical Sttistics, 2000(12), ISBN 7-81054-575-2 